\title{
INTERVIEW WITH NOAM CHOMSKY
}

\author{
Alessandro Boechat de Medeiros ${ }^{1}$
}

\begin{abstract}
Avram Noam Chomsky is a world-renowned linguist, philosopher and political activist. He is Professor Emeritus in the Department of Linguistics at Massachusetts Institute of Technology and recently became a laureate Professor in the Department of Linguistics at University of Arizona. He has been the leader of the generative enterprise in linguistic theory since its beginning, in the late fifties, and is considered by many the father of modern Linguistics. In fact, his views have influenced the whole field and established points of departure for research in formal syntax, phonology and even semantics.
\end{abstract}

Born in Philadelphia, in 1928, Chomsky started his undergraduate studies in Philosophy and Linguistics at the University of Philadelphia, in 1945. He concluded his Ph.D. in Linguistics in 1955, under the supervision of Zellig Harris, at the same University, with the thesis The Logical Structure of Linguistic Theory, a revolutionary work only published in 1975. Two years later, in 1957, he published Syntactic Structures (SS), one of his most famous linguistics books, considered by many a true revolution in the field. SS was in part based on The Logical Structure of Linguistic Theory, and exerted a great influence during late fifties and early sixties among language scholars, defining to a great extent linguistics research developed in the years to come. In 1959 he published his famous review of B. F. Skinner's book Verbal Behavior. The review presents a frontal and exhaustive critique of the behaviorist theory in a general way and also focally regarding language. Chomsky had other defining theoretical debates with Philosopher Michel Foucault ${ }^{2}$ and with Psychologist Jean Piaget ${ }^{3}$.

In the six decades since SS, Chomsky has creatively led different versions of the generative enterprise always boldly seeking to improve his own views on language and cognition. Alongside with his activities as a linguist, he has been an intense political activist having published over 100 books on war, freedom and power. Professor Chomsky's ideas have influenced a broad array of academic fields and he currently stands as one of the most cited scholars in history.

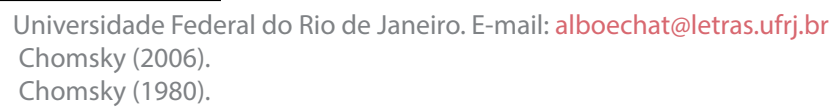


First of all, I would like to express our immense gratitude for this interview. We know about the limitations that are imposed by your intense agenda. But be sure our community will gain intangibly with your participation in this issue of Linguiftica.

1. The publication of Syntactic Structures (SS) marked a true revolution in the field of Linguistics, especially because by 1957 mastering a language was inadequately viewed as acquiring a system of habits and skills through repetition or conditioning. What is your personal view now of SS and its major claims? How do you assess its impact onto the field, sixty years after its first edition?

$S S$ was not initially intended for publication. It was based on notes for an undergraduate class at MIT, which at the time was mostly an engineering school. The class therefore began with their interests and training and the doctrines that were prevalent, often virtual dogmas, at the time, and discussed their limitations and flaws. The course then went on to what seemed to me then (and in general, now) to be more promising directions. The latter parts, the most important ones, were excerpted from a much longer work, Logical Structure of Linguistic Theory, unpublished (most of it was finally published years later, in 1975).

In the same year, 1957, I submitted to the journal Language my review of B.F. Skinner's Verbal Behavior $^{4}$, a critique of the radical behaviorism that was also highly influential at the time, particularly in Cambridge Massachusetts, one of the major centers of the emerging field of "behavioral science." $S S$ and the review are complementary, approaching the then-prevailing doctrines from different perspectives, proposing essentially the same program of research and inquiry along a path that differed sharply from views that were dominant at the time.

The two complementary publications were based on a few founding principles, which had been discussed from the early ' $50 \mathrm{~s}$ by three graduate students in Cambridge, close friends, who were dissatisfied with the prevailing doctrines (Morris Halle and Eric Lenneberg were the two others, also a few friends). We felt that a person's language should be viewed as a biological object, to be studied by the normal methods of the sciences, and that the approach should address the basic property of human language: that each language provides a digitally infinite array of hierarchically structured expressions that have interpretations at the interfaces with other organic systems, sensorimotor for externalization and conceptual for thought and action (the SM and $\mathrm{CI}$ interfaces, in more recent formulations). The approach departed sharply from reigning behaviorist and structuralist conceptions. It followed at once that two fundamental concerns are learnability (how can a child acquire the internal linguistic system?) and evolvability (how could the general principles - later called UG - that are instantiated in individual languages evolve?).

In retrospect, the critique seems to me sound, and the new directions explored there have indeed proved very valuable, though of course there have been great improvements and many new and important ideas and discoveries, from many sources.

Skinner (1957) 
As for the impact, it was one of many factors that led to creation of a discipline that barely existed at the time, with a great many researchers all over the world studying languages of broad typological range at a depth that was inconceivable at the time, raising new questions that were not even formulable then, often providing answers which themselves typically bring to light new and challenging problems. It is fair to say that more has been learned about language and its relation to other disciplines in these years than in the long and rich history of the study of language.

2. In the last years, following Strong Minimalist Thesis (henceforth SMT), you have been defending that UG be minimal, in the sense that its unexplained properties should be reduced to interface or computational efficiency (third factor) conditions and constraints. Also in Approaching UG from below, Problems of Projection, Problems of Projection - Extensions, and in the book you wrote with Robert Berwick, Why Only Us, you have advanced the idea that UG provides Merge, essentially, and that the parametric distinctions of the P\&P approach of the eighties and nineties should be transferred to externalization systems. Nevertheless, the P\&P approach seemed to fit in nicely with findings in cognitive neuroscience of vision and hearing, for instance, (Hubel and Weisel, 1962; Bekesy, 1961; Hensch, 2005) that describe critical periods in which cortical circuitry is materially shaped and organized by primary data. My question is about this last point. Could you say some words on how to go from that notion of parameters into one of representations in the externalization systems? What is the impact of this (new) conception of parameters on current theories of language acquisition and language change?

The P\&P approach quickly proved to be highly productive, leading to a vast expansion of studies of the kind mentioned above and also revitalizing psycholinguistic research into processing and acquisition and the study of language change in terms of parameter setting and identification. It also overcame a basic conceptual problem. Earlier approaches, from the first attempts to construct generative grammars in the late 1940s, had adopted a format-evaluation framework: UG provided a general format for grammars (I-languages in later terminology), and an evaluation metric selected among them, given primary linguistic data PLD. That approach did address the learnability problem: in principle, it provided a discovery procedure for I-language, but one that involved astronomical calculation and hence was entirely unrealistic. The P\&P approach in contrast restricted acquisition to a finite (though still huge) space of possibilities, offering hope for addressing the problem of learnability. But a major problem of evolvability arises: how did the parameters evolve? To address the joint questions of learnability (too many parameters) and evolvability efforts were undertaken at once to restrict the range of parameters. An early step was Hagit Borer's proposal that parameters should be restricted to formal features of the lexicon5. Another more recent proposal is the one you mention: that parameters should be restricted to externalization, a proposal that is quite natural in the light of recent evidence that externalization may be an ancillary system, not feeding the CI interface and not strictly linguistic in that it crucially involves not only I-language but also languageindependent SM systems. Some current work (notably by Samuel Epstein and his colleagues)

\footnotetext{
Borer (1984).
} 
suggests that at least some parameters may not be specified in UG at all (hence not have evolved) but rather indicate points at which I-language leaves options open, but that must be fixed for the SM systems. To illustrate, take what has been a paradigm example: the head parameter. There is mounting evidence that linear ordering is not part of I-language, though it is of course required by the SM system. The I-language therefore provides the hierarchical structure, but externalization to SM has to fix order. UG then has no such parameter, and there is no issue of evolvability. Of course, there still is a problem of learnability, approached in recent work by Ian Roberts and his colleagues in terms of a practical search procedure through alternatives left open by I-language. All matters under active investigation. The approach is quite consistent with the results on critical periods, a matter investigated by Eric Lenneberg in his classic study Biological Foundations of Language 50 years ago and pursued actively since.

3. In On Phases, you say that " $[\mathrm{t}]$ here has been much misunderstanding since the copy theory was proposed in Chomsky (1993), modifying earlier conceptions of movement by eliminating trace and indexing in favor of the NTC: that is, leaving the moved element unaffected instead of replacing it by an indexed trace (indexing is now superfluous, under identity). It has sometimes been supposed that a new "copy" is created, then inserted in the position of the moved element - all unnecessary and an alternative has been proposed in terms of "remerge," which is simply a notation for the copy theory as originally formulated in the most elementary terms" (footnote 17). In Problems of Projection (henceforth POP) you present convincing arguments against a copy operation and remerge. But how to implement Internal Merge without the creation of copies? Could you clarify this specific point a little further?

The operation Merge takes two syntactic objects $X, Y$ already constructed (including, as one case, elements from the lexicon) and constructs a new object $Z$ without changing either $X$ or $Y$ or adding any new structure. It is, therefore, the simplest computational operation. The new object formed can be regarded simply as the set $\mathrm{Z}=\{\mathrm{X}, \mathrm{Y}\}$. Suppose now that we have $X$ and want to merge to it some element $Y$. As a matter of logic, $Y$ can either be distinct from $X$ or non-distinct from $X$. In the latter case, by virtue of the way objects are constructed by Merge, $Y$ will be a term of $X$ - a member of $X$ or a member of a term of $X$ (a normal inductive definition). Suppose then that $Y$ is a term of $X$. Then Merge of $X$ and $Y$ forms $Z=\{X, Y\}$. Since $X$ is unchanged, it still contains the term $Y$, which is also merged to $X$. Therefore, $Z$ contains the element $Y$ twice: as a term of $X$ and as a term of $Z$. That is the standard situation of movement (chain-formation). There are no operations here beyond Merge in its simplest form.

4. In recent work, you have been defending the idea that Internal Merge (movement) is not an imperfection of language, but simply one of the options of Merge, and that to exclude this option would be in fact a stipulation. Internal Merge has been associated, then, to particular semantic functions, such as scope, focus/topic, and so on (e. g., On Phases). In POP, following again SMT, you advanced a framework in which, essentially, labels are not a by-product of Merge, and the task of selecting a label for (and therefore licensing) a syntactic object has been assigned to a Labeling Algorithm (LA). 
In this scenario, labels are important for the C-I interface, and Internal Merge can be triggered by the need of labeling certain sorts of syntactic objects with ambiguous labeling possibilities. Taking into consideration the framework of POP and your positions in previous works, my questions are: in POP and POP - Extensions, is the need of labeling syntactic objects the only trigger for displacement? If so, could all particular semantic functions associated to Internal Merge be properly explained by this unique triggering device?

That might turn out to be true, and if so, it is an important result. Of course, the "triggering" is sometimes multiple, as in successive-cyclic movement, an empirically well-established phenomenon.

5. In works like On Phases, Approaching UG from below, POP and POP - Extensions, you have adopted the idea of category-neutral roots advocated by the Distributed Morphology Literature (particularly, Marantz, 1997) and the Exoskeletal approach developed by Hagit Borer (Borer, 2005b, c). In these, roots are devoid of grammatical features. Some in the field (e. g., Ramchand, 2008), however, have criticized this conception of roots, based on the argument that roots should have grammatical features in order to be grammatical objects and interact with other grammatical objects, such as morpho-syntactic features or morphemes. What is your view on this debate about the nature of roots and their interaction with other grammatical objects?

I have tentatively adopted only a very narrow part of the DM and Exoskeletal approaches, namely that roots are category-neutral. That much leaves open the question whether some roots might have formal features not determined by their categorial label. But one way or another, I don't see why they would not be able to interact with other objects (grammatical/ formal or substantive). Thus I'm assuming that roots have semantic features that determine semantic selection/theta roles, merely to mention one example.

6. We are living a very sad socio-political moment in Brazil. Despite the fact that we have become more civilized and freer in the past 50 years, we are experiencing a general feeling of malaise for having lost some of the advancements we conquered in the past years. Many analysts argue that this failure mirrors a failure in our educational system. What are some positive examples to be followed in the world in which the explicit knowledge of linguistics as a result of a new educational policy was used to trigger more political articulation?

Sad times indeed, in many ways and for many reasons. Failure to develop critical thinking is always a problem. Linguistic research and training can certainly revitalize communities and help to cultivate clarity of thinking and understanding of scientific explanation and how to attain it -- the work of Ken Hale6, and of Maya Honda and Wayne O'Neil7, are impressive illustrations. And there are other possibilities. But the causes of today's malaise are much more direct and immediate, and will require serious engagement to overcome.

\footnotetext{
Hale (Ms.)

Honda $(1994,1999)$, Honda \& O’Niel $(1993,2007,2008,2017)$.
} 


\section{REFERENCES}

Békésy, G. v. (1961). Concerning the pleasures of observing, and the mechanics of the inner ear. Nobel Lecture.

Berwick, R.; Chomsky, N. (2016). Why only us: language and evolution. Abingdon: Taylor \& Francis.

Borer, H. 1984. Parametric syntax. Dordrecht: Foris.

. (2005). Structuring Sense, Vol I: In Name Only. Oxford: Oxford University Press.

. (2005). Structuring Sense, Vol II: The Normal Course of Events. Oxford: Oxford University

Press.

Chomsky, N. (1957). Syntactic Structures. Berlin: Mouton de Gruyter.

. (1959). A Review of B. F. Skinner's Verbal Behavior. Language, 35, 1, $26-58$.

. (1975). The Logical Structure of Linguistic Theory. New York: Plenum.

. (1980). Language and Learning: The Debate between Jean Piaget and Noam Chomsky (edited by Massimo Piattelli-Palmarini). Cambridge: Harvard University Press.

. (2006). The Chomsky-Foucault Debate: On Human Nature (with Michel Foucault). New York: The New Press, distributed by W.W. Norton.

. (2007). Approaching UG from below. In: SAUERLAND, U.; GÄRTNER, H-M (eds.).

Interfaces + recursion = language? Chomsky's minimalism and the view from syntax-semantics. Berlin: Mouton de Gruyter, p. 1-29.

. On Phases. In: OTERO, F. C.; ZUBIZARRET, M. L. (eds.). Foundational issues in Linguistic Theory: essays in honor of Jean-Roger Vergnaud. Cambridge: the MIT Press, p. 133-166. . (2013) Problems of Projection. Lingua, 130: 33-49.

. (2015) Problems of Projection - Extensions. In: DOMENICO, E. D.; HAMANN, C.; MATTEINI, S. Structures, Strategies and Beyond: Studies in honour of Adriana Belletti. Linguistik Aktuel, John Benjamins Publishing Company.

Hale, K. Navajo linguistics (part 1). Unpublished manuscript, Massachusetts Institute of Technology, Department of Linguistics and Philosophy, 1970-1972. 
Hensch, T. K. (2005) Critical period plasticity in local cortical circuits. Nat. Rev. Neurosci. 6:877-888.

Honda, M. Linguistic inquiry in the science classroom: "It is science, but it's not like a science problem in a book". MIT Occasional Papers in Linguistics 6. Cambridge, MA: MIT Working Papers in Linguistics, 1994.

. Developing an understanding of the nature of scientific inquiry through linguistics. In Anais do III SeminárioInternacional de Lingüística: Tema: A Lingüística como Ciência: Natureza do Método e Objecto (Proceedings of the 3rd International Linguistics Conference: Theme: Linguistics as Science: Nature of the Method and Object), 19-38. Porto Alegre, Brazil: Gráfica Epecê, 1999.

HONDA, M.; O’NEIL, W. Triggering science-forming capacity through linguistic inquiry. In The view from Building 20: Essays in honor of Sylvain Bromberger, ed. by Ken Hale and Samuel Jay Keyser, 229-255. Cambridge, MA: MIT Press, 1993.

.; PIPPIN, D. On promoting linguistics literacy: Bringing language science

to the English classroom. In Linguistics at school: Language awareness in primary and secondary education, ed. by Kristin Denham and Anne Lobeck, 175-188. Cambridge, UK: Cambridge University Press, 2007.

2008.Thinking linguistically: A scientific approach to language. Malden,

MA: Blackwell Publishers, 2008.

. On thinking linguistically. Revista Linguíftica / Revista do Programa de Pós-Graduação em Linguística da Universidade Federal do Rio de Janeiro. Volume 13, n.1 jan de 2017, p. 52-65. ISSN 2238-975X 1. [https://revistas.ufrj.br/index.php/rl]

HUBEL, D. H.; WIESEL, T. N. (1962). Receptive Fields, Binocular Interaction and Functional Architecture in the Cat's Visual Cortex. Journal of Physiology, 160: 106-164.

Lennenberg, E. (1967). Biological Foundations of Language. New York: Wiley \& Sons.

Marantz, A. No Escape from Syntax: don't try Morphological Analysis in the Privacy of your own Lexicon. University of Pennsylvania Working Papers in Linguistics: 4:2, p 201-225.

Ramchand, G. C. (2008). Verb meaning and the lexicon: A first phase syntax. Cambridge University Press.

Skinner, B. F. (1957) Verbal Behaviour. New York: Applenton-Century-Crofts. 